\title{
Violência escolar: um olhar dos professores
}

\author{
School violence: a view of teachers
}

Tamires Machado Barbosa ${ }^{1}$, Elisete Soares Traesel ${ }^{2}$

\section{Resumo}

O objetivo deste trabalho é investigar as repercussões das vivências de violência no ambiente escolar, através de uma pesquisa de campo qualitativa desenvolvida com professores. Considera-se importante este estudo para a psicopedagogia, a fim de auxiliar a comunidade escolar na prevenção e intervenção em situações de conflitos e de violência. Através da análise dos resultados, constatou-se que a forma de violência que mais ocorre na escola é a agressão verbal e humilhações através de palavras pejorativas. Os professores se sentem desconfortáveis, inseguros e impotentes diante dessa realidade, a qual causa impacto extremamente negativo em suas vidas, como desmotivação para trabalhar, medo, insegurança, impotência e percepção de seu despreparo para lidar com as situações violentas dentro da escola. Em relação às formas de prevenção à violência, os entrevistados apontaram a importância de uma maior participação e envolvimento da família no ambiente escolar e a implantação de políticas públicas na escola.

Palavras-chave: Violência. Professores. Psicopedagogo.

\begin{abstract}
The aim of this study is to investigate the impact of violence experiences happening at the school environment, through a qualitative field research conducted with teachers. We consider this study very important for the psychopedagogist role in the school to assist the community in prevention and intervention on situations of conflict or violence. By analyzing the results, it was found that verbal aggression and humiliation through hurtful words are the most common type of violence. Teachers feel uncomfortable, insecure and powerless against this reality, which causes extremely negative impact on their lives, as lack of motivation to work, fear, insecurity, powerlessness and perception of their unpreparedness to deal with violent situations at school. Regarding forms of violence prevention, interviewees indicated the importance of a greater family involvement and participation at school and the implementation of public policies in the school.
\end{abstract}

Keywords: Violence. Teachers. Psychopedagogists.

Esta obra foi licenciada com uma Licença Creative Commons - Atribuição 3.0 Não Adaptada.

\footnotetext{
${ }^{1}$ Centro Universitário Franciscano. E-mail: tata_psic@hotmail.com

2 Centro Universitário Franciscano. E-mail: elisetetraesel@unifra.br

Cad. de Pesq. Interdisc. em Ci-s. Hum-s. Florianópolis, Santa Catarina, Brasil, ISSN 1984-8951 v.14, n.105, p.88-119, ago/dez 2013
} 


\section{Introdução}

O presente trabalho aborda as repercussões na vida dos professores ao experienciarem a violência na escola, com o objetivo de investigar como esses sujeitos vivenciam tal situação no seu ambiente de trabalho. Para isso, foi desenvolvida, inicialmente, uma pesquisa de campo qualitativa com professores de uma escola pública localizada na cidade de Santa Maria, RS.

A caracterização ou a identificação de violência, especialmente no ambiente escolar, tem sido apresentada sob muitas dimensões e em diferentes contextos, por ser um fenômeno social bastante difícil de ser retratado, resultado de múltiplas determinações. Ou seja, analisar o fenômeno da violência é muito complexo, não apenas porque é um tema multifacetado, mas por trazer certo desconforto às vítimas, que relatam sentimentos como medo, agressividade, humilhações, ameaças, etc.

Segundo Neto (2005), o termo "violência escolar" diz respeito a todos os comportamentos agressivos e antissociais, incluindo também os conflitos interpessoais, danos ao patrimônio, atos criminosos, etc., cuja intervenção e solução geralmente dependem de fatores externos. Isto é, muitas vezes são necessárias ações interventivas que estão além da capacidade e da competência da instituição, a qual possui outra proposta - a educação formal - que visa a formar indivíduos capazes de refletir sobre seus atos, proporcionar o desenvolvimento da criatividade e de potencialidades do estudante.

Nessa direção, ao identificar e compreender as causas da existência da violência na escola, tanto física quanto psicológica, o professor deve ser instrumentalizado para problematizar essas situações com seus alunos (DANI, 2010). Assim, nesse contexto, as crianças e adolescentes passam a ser foco da preocupação para a família e para a comunidade escolar, justamente por viverem em uma sociedade que está em constantes transformações e repleta de manifestações violentas. Observa-se, inclusive, que a violência ocupa mundialmente grandes espaços em todos os meios de comunicação, apesar das poucas ações tomadas com o intuito de minimizá-la ou eliminá-la (ANSER et al., 2003).

Os sujeitos que vivenciam a violência escolar enfrentam consequências físicas e emocionais de curto e longo prazo, os quais podem causar dificuldades acadêmicas, sociais e emocionais (NETO, 2005). Dessa forma, entende-se que a Cad. de Pesq. Interdisc. em Ci-s. Hum-s. Florianópolis, Santa Catarina, Brasil, ISSN 1984-8951 
violência na escola é um problema social grave e complexo, pois afeta, principalmente, a saúde psíquica dos sujeitos escolares.

Para Silva e Ristum (2010), a violência na escola é um fenômeno que tem um forte incremento, atraindo a atenção de pesquisadores. Trata-se de um fenômeno construído a partir de relações históricas, sociais e culturais. É relevante pensar a violência como um termo complexo, pois sua repercussão ultrapassa o entendimento de agressão física. Por essa razão, a violência deve ser abrangida como um todo, o que torna sua descrição uma tarefa difícil (VELÁSQUEZ; CUNHA, 2008).

Enquanto os professores devem procurar saber lidar e resolver efetivamente os casos de violência na escola, a instituição deve buscar formas de intervenção e novas condições para prevenção dos comportamentos agressivos dos agentes. Para Neto (2005), a solução da violência dentro do espaço escolar pode ser obtida dentro da própria escola.

Ainda é extremamente importante destacar o papel do psicopedagogo no ambiente escolar, especialmente em um ambiente em que a violência esteja inserida, pois este profissional auxilia a estimular o desenvolvimento das relações interpessoais, bem como o estabelecimento de vínculos, ajudando a ampliar o olhar em torno da comunidade escolar que necessita de apoio.

Considerando os aspectos abordados acima, este trabalho priorizou 0 enfoque no papel do professor, no que diz respeito à violência escolar e objetivou compreender como os professores vivenciam a violência na escola, bem como identificar as repercussões da exposição à violência na vida desses profissionais.

\section{Referencial teórico}

A violência é, atualmente, considerada um dos fenômenos sociais que mais cresce, e tem sido um dos temas mais debatidos e pesquisados, devido a sua relevância, principalmente quando se trata do ambiente escolar. Nesse âmbito, são presenciados atos violentos em sala de aula, especialmente relacionados aos professores, gerando, assim, situações extremamente constrangedoras, humilhantes e perigosas. Conforme proposição de Chrispino e Dusi (2008, p. 598), "o problema é verdadeiro e concreto, é amplo e se complica a cada dia". 
As formas de violência nas escolas estão aumentando em frequência e gravidade no cenário mundial, as quais estão relacionadas à rapidez das mudanças histórico-sociais, ao "mal-estar da civilização", à "crise da escola", à "desagregação da família" e a outros fatores (GALVÃO, et. al., 2010).

Ao nos referirmos à violência no contexto escolar, assombram-nos as notícias dos jornais, TV, revistas, internet e outros meios relacionados à escola e à violência. De acordo com Pereira (2003, p. 28), "nunca a violência esteve tão presente em nosso dia a dia quanto agora", pois a todo o momento ocorrem episódios do gênero, promovendo sentimentos de insegurança, medo, entre outros, nas pessoas que vivenciam os episódios violentos.

Para Velásquez e Cunha (2008), a instituição escolar vem, ao longo do tempo, modificando seus hábitos e crenças, sem que se firmem e solidifiquem em novos costumes e pensamentos, assim, cotidianamente recebem seus alunos que extravasam suas pulsões, ansiedades e expectativas. Diante dessa realidade, os professores se sentem desorientados e mal preparados para enfrentar esse cenário caótico. Os docentes, muitas vezes, assumem uma postura de indiferença, a qual os leva, juntamente com os alunos, a não terem suas vontades e necessidades supridas no contexto escolar, descaracterizando, dessa forma, a própria escola (OLIVEIRA; MARTINS, 2007).

Segundo Witter (2010), a violência afeta a saúde biopsicossocial do indivíduo, consequentemente, afeta a saúde da sociedade, podendo levar a consequências trágicas. Assim, a violência pode se manifestar de diversas formas nas práticas cotidianas escolares, como o desrespeito, os preconceitos, as incivilidades, os problemas psicológicos e mesmo a ignorância. Embora a violência esteja presente em todos os níveis de escolaridade, ela assume formas, tipos e graduações diferentes em cada um deles (WITTER, 2010).

Conforme Souza (2008), as formas de violência mais graves, como as psicológicas, ocasionadas por ameaças, humilhações, intimidações, rejeição e desrespeito, nem sempre são percebidas. Assim, a suposta invisibilidade desse tipo de violência contribui para se gerar um ambiente de segregação na escola, que "em vez de ser um lugar seguro e de integração social, de socialização e resguardo, [...] se tornou um cenário de ocorrências violentas" (ORTEGA; REY, 2002, p. 9). 
Santos (2001), ao retratar a violência escolar, constata a necessidade de estarmos conscientes ao analisar os fenômenos da violência escolar, pois se trata de uma relação professor/aluno, em que este último é desfavorecido, por integrar uma relação de poder, que, por consequência, o torna vitimado. Dessa maneira, frequentemente há dois personagens na situação de violência: o agressor e o agredido (vítima).

Portanto, a compreensão das relações entre o contexto escolar e a violência passa pela reconstrução das relações interpessoais existentes nos espaços da escola. Esse fenômeno social não se restringe apenas ao homem contemporâneo, mas ele acompanha a humanidade desde os tempos mais remotos (SOUZA, 2008).

A agressividade é inerente ao ser humano, que busca satisfazer suas necessidades básicas, manifestando, assim, seus impulsos agressivos entre os seres da mesma espécie, ao invés de outras soluções que poderiam ser empregadas. Para Souza (2008, p. 122), "o uso da violência, como meio para resolver conflitos pessoais, significa, por parte dos homens, deixar de utilizar o instrumento que os diferenciam dos outros animais, o diálogo".

Referindo-se aos atos agressivos na infância, Fernandéz (2001) diferencia a agressividade necessária e sadia, da agressão patógena. A agressividade necessária abre o espaço para o simbólico e a outra bloqueia o espaço da criatividade, dificultando a possibilidade de pensar. Ainda no que tange a agressividade, Neto (2005, p. 165) afirma que "a agressividade nas escolas é um problema universal".

A violência tem sido um problema de saúde pública relevante e cada vez mais crescente, com consequências graves, tanto individuais quanto sociais, e evidente principalmente entre os jovens, os quais aparecem mais nos dados estatísticos apontados na mídia e em pesquisas científicas. Uma das formas de violência escolar, que ocorre tanto de maneira explícita quanto implícita, é o bullying. Segundo Neto (2005), o bullying é uma afirmação de poder interpessoal praticada através da agressão, ou seja, compreende todas as atitudes agressivas, intencionais e repetidas, realizadas por uma ou mais pessoas contra o outro, causando dor e angústia, dentro de uma relação desigual de poder.

Conforme apontam Priotto e Boneti (2009), atitudes como ofender, ignorar, excluir, ferir e humilhar sempre foram encontradas nas escolas, e cada vez mais 
esses tipos de comportamentos têm se estendido para fora da escola, invadindo a vida pessoal do indivíduo como, por exemplo, através da internet e de celulares. Esses tipos de comportamentos agressivos que ocorrem no contexto escolar são percebidos como ações naturais e comuns, tanto por professores quanto pelos pais dos estudantes.

É relevante destacar o papel dos educadores, especialmente do professor que deve suscitar investimento em seu conhecimento, tornando-se crítico e sendo capaz de fazer a diferença no desenvolvimento educacional dos seus alunos, para juntos amadurecerem. De acordo com Pereira (2003), entende-se que a escola facilita o exercício da cidadania e constrói espaços para que não haja a violência. Dessa forma, estará cumprindo sua função social que é possibilitar o crescimento e o desenvolvimento humano.

Ainda, faz-se necessário enfatizar a importância do profissional da psicopedagogia, pois este propõe e auxilia a escola a realizar mudanças e projetos educacionais, visando à descoberta e ao desenvolvimento dos alunos, bem como ajudá-los a olhar o mundo em que vivem e a interpretá-lo, sendo capazes de interferir com segurança e competência (SOARES; SENA, 2012). Desse modo, é extremamente relevante a contribuição do psicopedagogo na escola, diante do desafio de se lidar com a violência.

Para Galvão et al. (2010), é imprescindível a escola tornar-se um lugar de transparência, ao invés de um ambiente onde falta nitidez nos valores sociais e onde há indefinições das normas e limites, pois a sociedade se transforma à volta da escola, assim como seus alunos. Dessa maneira, a escola propicia ao discente um ambiente com espaço para a construção do diálogo, favorecendo autonomia e trocas de pontos de vista, contribuindo para a aprendizagem.

Conforme Oliveira e Martins (2007), a maneira como a violência se expressa atualmente aponta para a constatação da ausência da palavra, ou seja, falta de diálogo que emerge apenas a partir do interesse dos envolvidos: a família, a escola e a mídia. Porém, o que se percebe é que as instituições escolares e a família permanecem caladas, enquanto a mídia transmite informações de modo sensacionalista.

A sociedade acredita que a escola é o espaço ideal para reproduzir valores considerados importantes para sua manutenção. Porém, a família em crise e as 
transformações sociais contemporâneas delegam à escola funções educativas que, historicamente, eram de sua responsabilidade, o que incorreu em mudanças no perfil comportamental do aluno (CHRISPINO; DUSI, 2008).

Reafirmando, Velásquez e Cunha (2008) referem que a escola desloca a responsabilidade pelas práticas agressivas entre os alunos e professores para a família, o que leva à ausência de diálogo e de espaços de socialização entre os sujeitos.

Para Dani (2010), a escola e a família são os meios de experiência mais significativos, capazes de influenciar no processo de construção da personalidade moral do aluno. Na escola, essa influência tem origem a partir das práticas pedagógicas, que propiciam ao aluno internalizar valores durante o seu desenvolvimento sócio-moral.

Cotidianamente, ao fazer parte da escola, a violência torna-se um fenômeno, o qual é fruto de diversos fatores como desigualdade entre as classes sociais, imposição de regras coletivas e reprodução do modelo que os alunos vivenciam em suas famílias (OLIVEIRA; MARTINS, 2007).

Conforme Anser et al. (2003), a escola sofre os reflexos dos fatores originados na violência, gerando conflitos manifestados dentro da sala de aula, e, consequentemente, comprometendo o aprendizado e as relações interpessoais da comunidade escolar.

A violência no espaço escolar manifestada através do comportamento dos alunos lança o professor a duas possibilidades: a de um ensino libertador ou a de uma realidade insuportável, onde são estabelecidas regras, controles, punições e dominações para disciplinar os alunos rebeldes, tornando-o um profissional autoritário (OLIVEIRA; MARTINS, 2007). Assim, a escola torna-se parte do problema, mas pode tornar-se peça fundamental para a eliminação e/ou diminuição da violência.

Conforme Dani (2010), ao identificar e compreender as causas da existência da violência, seja ela física ou psicológica, o professor deve ser instrumentalizado para problematizar essas situações com seus alunos. Esse tipo de atitude propicia um ambiente agradável e favorável ao diálogo, proporcionando aos alunos a oportunidade de expressarem seus pontos de vista. 
Ou seja, deve haver a intervenção do psicopedagogo neste contexto de violência, com o intuito de promover um trabalho ligado à subjetividade do individuo para que os professores possam posicionar-se de maneira diferente, livres e criativos em respeito a eles mesmos e, consequentemente, para que possam ensinar melhor e ressignificar o aprender dos seus alunos.

Dessa forma, as experiências de trocas professor-aluno contribuem para a conquista da aprendizagem de capacidades como autonomia, reciprocidade e sensibilidade moral (DANI, 2010). Portanto, através da conversa e reflexão entre professor e aluno poderão ser minimizadas e/ou solucionadas as situações violentas no ambiente escolar e, consequentemente, ocorrer o desenvolvimento e a aprendizagem do aluno sem prejuízos.

Assim, de acordo com Ortega e Rey (2002), a existência de um clima agradável no ambiente escolar e na convivência depende das possibilidades de cada indivíduo expor o que sente e o que pensa, para permitir que os conflitos sejam solucionados, tão logo surgem, já que a comunidade escolar e a convivência são dinâmicas. Para Santos (2001, p. 107), "o reconhecimento da violência no espaço escolar como uma das novas questões sociais globais parece ser um caminho interpretativo fecundo desse fenômeno social caracterizado como um enclausuramento do gesto e da palavra".

Diante da violência na escola, o reconhecimento das suas manifestações e a sua complexidade são os maiores desafios. Ainda, o ambiente escolar deveria possibilitar uma atuação ampla na prevenção da violência, proporcionando um lugar de elo de confiança e amizade entre professores e alunos (NJAINE; MINAYO, 2003).

Segundo Anser et al. (2003), é fundamental investir em orientações e apoio aos professores, através de estratégias de aperfeiçoamento da prática pedagógica e da relação professor-aluno, em conjunto com as famílias, buscando a prevenção dos conflitos e dos problemas. Para Ortega e Rey (2002), a percepção de inserção em uma comunidade pode facilitar o combate à violência, como consta na passagem "um aspecto fundamental para reverter um quadro de violência é a construção de um senso de pertencimento à comunidade" (ORTEGA; REY, 2002, p. 9). Em contrapartida, não é essa situação descrita que se tem apresentado na realidade escolar, pois é preciso que a escola tenha regras claras e seja democrática, fazendo com que todos se sintam pertencentes à instituição escola. 
Além disso, não se pode desconsiderar o clima de insegurança e medo presente na escola, o qual é intensificado pela exploração do assunto pelas diferentes mídias, o que gera mais insegurança aos professores, tornando-os frágeis e impossibilitados de realizar qualquer intervenção na redução ou eliminação da violência no espaço escolar.

Os pais ou responsáveis pelos alunos passam a sua responsabilidade de preparar os jovens para a vida aos professores. Estes relatam o seu despreparo e a ausência do apoio familiar para lidar com essa realidade violenta (NJAINE; MINAYO, 2003). Todavia, o ideal seria que toda a comunidade escolar se envolvesse em conjunto para minimizar ou solucionar as cenas violentas dentro do espaço da escola.

Conforme Ortega e Rey (2002), o combate e a prevenção da violência não podem ser feitos de maneira determinista nem fechada, pois são necessárias estratégias que modifiquem o padrão de relacionamento na comunidade escolar, as quais envolvem alunos, professores, direção e pais.

Entretanto, percebe-se que, para os professores abordarem a questão da violência dentro da sala de aula, é preciso a ruptura de preconceitos, medos e silêncios, tornando-se um desafio a mais a ser enfrentado. A necessidade de diálogo envolvendo toda a comunidade escolar, onde ocorrem as relações de conflitos e tensões violentas, precisa ser urgentemente revista pela escola e por todos aqueles ligados a ela. Através dessa atitude, com o diálogo, que envolve os educadores e educandos, é que haverá uma escola transformadora, a qual redefinirá seus objetivos e apresentará regras claras, proporcionando um ambiente propício ao desenvolvimento humano e aprendizagem escolar.

É esperado que a escola seja um ambiente seguro e saudável, onde os professores e estudantes possam desenvolver ao máximo seus potenciais intelectuais e sociais. Mas, para isso, não se deve admitir que os agentes escolares sofram violência e danos físicos e/ou psicológicos ou que sejam testemunhas de tais atos, calando-se devido ao medo de sofrer represália. Para isso, é necessário o envolvimento de toda a comunidade escolar (professores, funcionários, alunos e família) com o objetivo de inserir o tema na escola, a fim de problematizar causas e prevenções. 
Conforme Marriel et al. (2006), concerne à escola refletir e discutir temas que afligem a sociedade em seu cotidiano, entre os quais está a violência, suas formas de prevenção e as possíveis consequências no desenvolvimento dos seus alunos. É dentro do espaço escolar que ocorrerá a formação de opiniões e atitudes, podendo o desenvolvimento pessoal ser tanto aprimorado como prejudicado.

Diante da realidade já citada, é primordial que haja uma reflexão a respeito do fenômeno da violência escolar e a contribuição da psicopedagogia nesse processo, a qual tem o intuito de compreender e auxiliar nos fatores que influenciam e prejudicam a aprendizagem e as inter-relações dentro da escola.

Ainda, é fundamental que professores e alunos redefinam seus papéis, bem como os da escola e da família, que tem suas funções a cumprir. Para tal efetivação, é necessário que a escola seja um espaço de possibilidades de construção humana, onde as relações interpessoais do seu cotidiano signifiquem a formação de valores, linguagens e sentimentos (VELÁSQUEZ; CUNHA, 2008).

\section{Metodologia}

\subsection{Abordagem da pesquisa}

$O$ presente trabalho foi realizado através de uma pesquisa qualitativa (MINAYO, 2007). Trata-se de um tipo de pesquisa construído no decorrer do seu desenvolvimento e que não busca enumerar ou medir eventos. A pesquisa qualitativa inclui a obtenção de dados descritivos, mediante contato direto e interativo do pesquisador com a situação objeto de estudo. Nessa direção, Minayo (2007) considera que, neste tipo de pesquisa, a interação entre o pesquisador e os sujeitos pesquisados é essencial. Ela responde a questões muito particulares, trabalhando com o universo de significados, motivos, aspirações, crenças, valores, atitudes, o que corresponde a um espaço mais profundo das relações (MINAYO, 1994).

Essa pesquisa é classificada como exploratória, que, para Gil (1995), tem por finalidade desenvolver, esclarecer e modificar conceitos e ideias com vistas à formulação de problemas mais precisos ou hipóteses pesquisáveis para estudos posteriores. Segundo Gil (1995), a pesquisa exploratória é desenvolvida com o objetivo de proporcionar uma visão geral de determinado fato, principalmente Cad. de Pesq. Interdisc. em Ci-s. Hum-s. Florianópolis, Santa Catarina, Brasil, ISSN 1984-8951 
quando o tema escolhido é pouco explorado e torna-se difícil sobre ele formular hipóteses precisas e operacionalizáveis.

Dessa forma, o instrumento de coleta dos dados para o desenvolvimento deste estudo foi a entrevista focalizada, realizada individualmente, com questões focadas nos sentimentos e vivências relativos à violência escolar. A entrevista focalizada é livre, mas enfoca um tema bem específico, permitindo ao entrevistado falar livremente sobre o assunto, porém quando este se desvia do tema original, deve ser interrompido (KERLINGER, 1980).

Para Minayo (2008), a entrevista focalizada se destina a esclarecer apenas um determinado problema. Esse tipo de entrevista tem com objetivo explorar a fundo alguma experiência vivida em condições precisas, em que o entrevistador concede ampla liberdade para o indivíduo se expressar sobre essa experiência específica (KERLINGER, 1980).

Segundo Marconi e Lakatos (1999), na entrevista focalizada, o entrevistador tem liberdade de fazer as perguntas que quiser, sondando razões e motivos. É possível fornecer esclarecimentos, mas, para isso, são necessárias habilidades e perspicácia.

Com relação aos resultados obtidos, eles foram submetidos ao método de análise de conteúdo, sendo que, posteriormente, foram construídas categorias a partir da entrevista focalizada. Segundo Bardin (2004), o agrupamento em categorias possibilita uma sistematização e discussão dos resultados, organizandoos, relacionando-os e efetuando as verificações propostas nos objetivos do estudo em questão.

\subsection{Participantes e local da pesquisa}

Os participantes da pesquisa foram professores de uma escola pública da cidade de Santa Maria, RS, que já vivenciaram algum tipo de violência no ambiente escolar. A pesquisa foi desenvolvida na escola, a partir da colaboração de cinco professores que aceitaram o convite de participação, e que assinaram o Termo de Consentimento Livre e Esclarecido - TCLE. 


\subsection{Procedimentos de coleta de dados}

Foi utilizada como instrumento desta pesquisa a entrevista focalizada com questões construídas a partir dos objetivos da pesquisa. As entrevistas foram gravadas em fita cassete e seu conteúdo foi transcrito. Após a transcrição, as fitas foram destruídas.

\subsection{Procedimentos éticos}

Os professores da escola pública que concordaram em participar da pesquisa foram convidados a assinar o Termo de Consentimento Livre e Esclarecido - TCLE. Após a assinatura do Termo, foi aplicado o instrumento de pesquisa e foram usadas siglas (P1, P2, P3, P4 e P5) para representar os participantes nos relatos, a fim de preservar a identidade dos participantes.

Salienta-se que a pesquisa somente foi iniciada após a autorização da escola, formalizada através de assinatura de carta de autorização, a qual foi encaminhada ao Comitê de Ética da UNIFRA, em anexo ao projeto desta pesquisa, o qual foi submetido à apreciação do Comitê de Ética e Pesquisa do Centro Universitário Franciscano - UNIFRA e foi aprovado.

\subsection{Procedimentos de análise dos dados}

A análise e interpretação dos resultados foram efetuadas através do método de análise de conteúdo, o qual suscitou a elaboração de categorias de análise. Para Marconi e Lakatos (1999), a análise e a interpretação dos dados é a tentativa de evidenciar as relações existentes entre fenômeno estudado e outros fatores.

Segundo Bardin (2004), para classificarmos os elementos em categorias, fazse necessária uma investigação dos elementos em comum existentes entre eles, sendo que o agrupamento em categorias possibilita uma sistematização e uma discussão dos resultados, organizando-os, relacionando-os e efetuando as verificações propostas nos objetivos da pesquisa.

A análise de conteúdo é usada para descrever e interpretar o conteúdo de toda classe de documentos e textos, conduzindo a descrições sistemáticas, 
qualitativas ou quantitativas, a fim de interpretar as mensagens para compreender os seus significados em um nível que vai além de uma leitura comum (MORAES, 1999).

\title{
3 Apresentação e discussão dos resultados
}

\subsection{Formas de violência vivenciadas no dia a dia da escola}

Não há como ignorar a questão da violência, quando ela se faz presente no espaço educacional, pois a comunidade escolar (professores, alunos, funcionários e pais) encontra-se obrigada a conviver com os atos violentos, os quais fazem parte do cotidiano da escola. Constatou-se a partir dos relatos que a violência sofrida e praticada na escola se apresenta sob diversas formas, mas, principalmente, por agressões verbais, humilhações, discussões e ameaças.

No que diz respeito à vivência de algum tipo de violência na escola, todos os professores entrevistados relataram já ter alguma experiência desse tipo. Ao relatar as agressões verbais, o entrevistado P1 diz:

\begin{abstract}
Ah, as verbais, né? São as mais comuns, xingamentos. [...] Até o jeito de falar em si, eu já acho que é, porque é um tipo de violência, né? Eu encaro dessa maneira. Então, eu procuro nos primeiros dias de aula já conversar com eles (alunos) sobre as expressões que eu não concordo, nem eu uso com eles, e nem eles podem usar entre eles. A pior delas, para mim, é o 'cala a boca'.
\end{abstract}

A partir desse relato, retoma-se a afirmação de Gonçalves e Sposito (2002), os quais propõem que há um momento de mudanças no padrão de violência nas escolas públicas, onde estão ocorrendo com mais frequência as práticas de agressões verbais e as ameaças.

O entrevistado $\mathrm{P} 2$ relatou:

[...] o tipo de violência que mais tem aqui é a agressão de aluno, a verbal, né? Não é agressão física. Brigas especificamente não têm, mas tem verbalmente. Assim, eles têm uma certa [sic] falta de respeito entre eles, exclusão entre colegas, por algum tipo de preconceito entre eles, né? Essa é a violência que eu vejo. Por opção sexual também, preconceito, né? Daí, é um tipo de violência mais verbal, é aquela coisa mais dissimulada, não é aparente $[\ldots]$. 
Conforme Marriel et al. (2006), a violência não física (violências verbais, humilhações, discriminações, segregações e desvalorização com palavras e atitudes de desmerecimento), muitas vezes, é disfarçada, mascarada e de difícil diagnóstico, sendo experiências aniquiladoras, tanto para os alunos quanto para os professores.

Neste sentido, cabe à escola debater e refletir as questões que afligem o cotidiano de sua comunidade escolar, justamente por se tratar de um tema tão delicado e pertinente, devendo possibilitar formas de prevenção e reflexão sobre as possíveis repercussões que incidirão no seu espaço educacional.

Ainda quanto a esse tema, o participante P3 comentou:

Bom, a mais comum que eu vejo no ensino fundamental, nessa escola, é o bullying. Eu digo, assim, [sic] da perseguição. Perseguir, assim [sic], de botar apelido, de chamar de gordinho, de não sei o quê, para ofender mesmo, né? Para agredir mesmo. É o mais comum [...].

Conforme o relato, percebe-se que a agressividade entre os pares é identificada pelos estudantes nas atitudes agressivas explícitas ou veladas, as quais permeiam as relações interpessoais na escola (NJAINE; MINAYO, 2003).

A existência de humilhações, discriminações e ofensas verbais tem ocorrido comumente nas escolas brasileiras. A presença do bullying tem sido flagrada constantemente entre os alunos, levando a consequências psicológicas graves nas vítimas, por isso é dada importância a estudos e pesquisas sobre o tema nos últimos anos, no mundo todo. Para Marriel et al. (2006), o termo em inglês se refere a uma denominação diferenciada para a violência no âmbito escolar, evidenciando uma repercussão negativa da violência entre os pares desse contexto.

Ainda comentando sobre as agressões verbais, o participante P5 relatou: "é mais a verbal: é o bullying. Eles agridem uns aos outros com palavrões, apelidos. É mais verbalmente". Com esses constantes comportamentos agressivos e violentos, antes não vistos como tais, tem-se dado importância ao tema, com o objetivo de intervir no ambiente escolar. De acordo com Marriel et al. (2006), o bullying é caracterizado por atos repetitivos de opressão, tirania, agressão e dominação de algumas pessoas sobre outras.

Outro aspecto bastante relevante constatado na pesquisa diz respeito ao fato de os relatos sobre as agressões verbais e o desrespeito à figura do professor estarem muito presentes no cotidiano da escola. O participante P2 relatou:

Cad. de Pesq. Interdisc. em Ci-s. Hum-s. Florianópolis, Santa Catarina, Brasil, ISSN 1984-8951 v.14, n.105, p.88-119, ago/dez 2013 
[...] mas, a violência [...] que eu acho mais problemática [...] [é] a maneira do aluno falar com o professor, a falta de respeito, né? Até esses dias, eu estava comentando com as gurias [professoras], [sic] que o jeito que uma menina falou comigo em sala de aula, né? Eles não respeitam os profissionais, eles tentam passar do limite. Mas eu vejo que, muitas vezes, essa questão é assim, em palavras, né? Eles falam de forma agressiva com o professor, eles querem impor a maneira de ser [...].

Segundo pesquisa realizada com docentes por Njaine e Minayo (2003), é confirmado que, na visão dos professores, os seus alunos apresentam um comportamento agressivo e intolerante, através do qual muitos aspectos negativos da relação professor-aluno ficam evidentes. Nessa direção, Marriel et al. (2006, p. 42) afirmam que "a relação professor-aluno é, muitas vezes, permeada pela falta de limites e de respeito".

Nos depoimentos dos entrevistados, aparecem as queixas sobre o relacionamento professor-aluno, o qual é composto por conflitos, tensões, falta de limites e regras. O participante P2 ainda relata: "[...] [tudo] tem que ser da maneira que eles querem. E eles não aceitam que tu coloque [sic] regras e limites. Isso é o que vejo, é o da violência verbal com o professor [...]". Dessa forma, Njaine e Minayo (2003) vêm ao encontro disso quando afirmam que na relação entre professor-aluno não se consegue demarcar os limites de manifestações para essas agressões.

Ainda sobre esse aspecto, o participante P1 relatou: "[...] eu procuro, na minha aula, fazer o possível para se organizarem. Claro que não é sempre que se consegue, às vezes, é difícil, mas a gente vai tentando, né? [...]". Fica claro que, devem ser apontadas medidas eficazes para uma boa relação entre professor-aluno, como dar a prioridade ao diálogo. Segundo Galvão et al. (2010), em um estudo realizado, professores e alunos indicaram algumas medidas possíveis de serem incorporadas ao espaço escolar, tais como: diálogo, debates, palestras, seminários, disciplinas sobre o tema e comunicação mútua entre aluno-professor e escolacomunidade.

Já no que diz respeito aos conflitos entre estudantes, e se há violência entre eles, o entrevistado $\mathrm{P} 4$ relata:

Em questão aluno, sim. Em observar o aluno se digladiando, brigando com outro aluno, com certeza. Falando palavras ásperas [sic], encenando dar pelo menos socos, pontapés, arrastando classes. Não somente dentro

Cad. de Pesq. Interdisc. em Ci-s. Hum-s. Florianópolis, Santa Catarina, Brasil, ISSN 1984-8951 v.14, n.105, p.88-119, ago/dez 2013 
dessa redondeza aqui, mas em outras também. Claro que se vivencia bastante isso, em palavras ásperas [sic], em palavrões, em levantarem e se agarrarem como se estivessem querendo brigar de maneira áspera [sic], de maneira com socos, agressões [...].

Para Pereira (2003), as brigas e as agressões verbais entre os alunos são as mais frequentes e as manifestações mais explícitas são: chutes, empurrões, brincadeiras e palavras agressivas. Assim, constatou-se que há situações de conflitos entre os estudantes dentro da escola, ou seja, é na relação dos alunos onde a violência se evidencia de forma mais clara.

Portanto, frente à vasta gama de possibilidades, a violência pode manifestarse de forma explícita, dentro do contexto escolar, através do comportamento agressivo dos alunos, nas brigas, agressões verbais, humilhações, ameaças, provocando, assim, uma série de consequências negativas no cotidiano escolar. As formas de violência mais sutis e de menor visibilidade, porém não menos importantes, também fazem parte do dia a dia da escola (MARRIEL et al., 2003).

Sendo assim, constatou-se que essas formas de violência são corriqueiras e enraizadas na prática escolar, mas necessitam de uma transformação, devido às consequências das práticas cotidianas de preconceito e de discriminação.

Certamente, a atuação de um psicopedagogo no ambiente escolar seria bastante relevante, no sentido de orientar os professores quanto aos indícios dessas formas de violência, e para poder desenvolver maneiras eficazes de prevenção e intervenção das formas de violência dentro da escola.

\subsection{As causas da violência na escola: a ótica dos professores}

É muito difícil definir as principais causas da violência que estão presentes no contexto escolar. Elas podem ser inúmeras e diversificadas, como, por exemplo, provenientes da própria relação pessoal, política, interação social, cultural, econômica, etc.

Ao serem solicitados a dar sua opinião sobre as causas da violência na escola, os professores apontaram como principais motivos: agressividade entre os alunos para afirmação da própria identidade, negligência da família e leis que protegem o menor de idade. 
Em relação à agressividade entre os pares, o entrevistado $\mathrm{P} 1$ relatou: "[...] são mais as verbais, até o jeito de falar. Tem uns que estão entrando na adolescência, principalmente os do $6^{\circ}$ ano. Eles são mais [agressivos], eles mesmos se confundem [...]". Ainda em relação às agressões entre os pares, o entrevistado P3 relatou que há dois tipos de violência na escola: "[...] [acontece] tanto essa parte da agressão psicológica, verbal, no caso de chamar o coleguinha de tal coisa, de querer machucar, de agredir, em fazer ele se sentir mal, quanto à física [...]".

Dessa forma, pode-se observar que os professores entrevistados justificam, como causa de violência, a fase da adolescência, pela qual seus alunos passam e que leva a essas atitudes agressivas nas relações. Para Njaine e Minayo (2003), a agressividade entre os alunos é identificada nas atitudes agressivas explícitas ou veladas e permeiam as relações interpessoais na escola.

Ao relatar sobre a negligência da família, o participante P1 comentou:

Se tivesse um maior envolvimento [da família], seria melhor. Porque a gente marca uma reunião com os pais, sempre vem meia dúzia, [...] aqueles que não precisariam estar ali. Isso é a realidade de todas as escolas, acho eu, né? Então, acho que há é esse descrédito da parte da família [...].

Ainda, ao referir sobre o descaso da família, o entrevistado P3 relatou: "[é importante] ter uma aproximação maior da família com a escola. Não ter esse distanciamento. Parece que uma está contra a outra. O professor culpa a família e a família culpa a escola [...]".

Como se pode perceber, um aspecto muito destacado foi a falta de comprometimento da família na vida dos estudantes e o descaso da comunicação família-escola. Estudos realizados por Njaine e Minayo (2003) apontam que professores criticam a família, acusam-na por sua pouca participação na educação e pela atitude ausente dos pais no cotidiano dos filhos.

A família desempenha um papel primordial no desenvolvimento dos alunos, mas, muitas vezes, os pais não querem enxergar a realidade das atitudes e dos comportamentos de seus filhos. O vínculo entre pais e filhos é essencial para o bom desenvolvimento e para a estruturação da personalidade dos jovens. A atuação do psicopedagogo se propõe a incluir os pais no processo de desenvolvimento de seus filhos, através de reuniões, a fim de possibilitar o acompanhamento do trabalho realizado junto aos professores (SOARES; SENA, 2012).

Cad. de Pesq. Interdisc. em Ci-s. Hum-s. Florianópolis, Santa Catarina, Brasil, ISSN 1984-8951 v.14, n.105, p.88-119, ago/dez 2013 
No que diz respeito à violência verbal, o participante P2 afirmou sobre os estudantes:

[...] eles não aceitam que tu coloque [sic] regras e limites. Claro, se tu for um professor bem rígido, que tu seja totalmente fechado, daí, [...] todo mundo te ouve, mas também ninguém fica satisfeito com tua aula, porque tu tá [sic] assumindo uma postura meio autoritária demais. Agora, se tu for um professor que procura conversar e ter diálogo com eles, eles não vão encontrar um meio para te agredir [...].

Para Galvão et al. (2010), através de estudos realizados, verificou-se que, na opinião dos professores, há um alto nível de gravidade de brigas, insultos, agressões aos professores e intimidações psicológicas. Ainda, os autores afirmam que os educadores não consideram como ato de violência o professor gritar, insultar e intimidar os alunos por meios psicológicos.

Sobre a agressividade entre os alunos para autoafirmação da identidade, 0 entrevistado $\mathrm{P} 4$ relatou:

[...] sempre existe interferência dos próprios colegas. Eles estão naquele meio, eles não estão sozinhos; os dois que estão a brigar. Existe já a parcela do lado de lá e a parcela do lado de cá. E eles mesmos tentam se apaziguar. Uns instigam, outros não. Outros tentam apaziguar; quando acontece aquela coisa mais violenta [...].

Diante disso, Ristum e Bastos (2004) afirmam que trabalhos realizados com professores apontam que a maior incidência de ameaças e agressões ocorre entre os alunos.

Outro aspecto que foi constatado nas entrevistas diz respeito às leis que amparam o menor de idade e que os estudantes usam para respaldar a violência. Assim, o entrevistado $P 5$ relatou:

[...] eu acredito que nós precisamos de mais apoio nesse aspecto. A gente fica assim, quase que, digamos assim, sem reação para saber como proceder. Porque o menor é muito protegido. [...] Existem os deveres, e estão muito esquecidos, [...] esquecem que também têm deveres conosco $[\ldots]$.

Portanto, percebeu-se que, diante dessa situação, o professor fica desamparado, inseguro e desconfortável, pois se sente despreparado para lidar com tal realidade. Assim, constatou-se que os professores se apresentam desinformados e que há a necessidade de se buscar uma alternativa capaz de amenizar as causas 
da violência dentro do cotidiano da escola, pois esse não é somente um espaço para ensinar conteúdos educacionais tradicionais, mas, também, para os estudantes aprenderem a conviver, se relacionar, adquirirem valores e crenças, desenvolverem senso crítico e segurança.

Sendo assim, fica claro que um dos passos para o clima escolar se tornar favorável é o uso do diálogo, a expressão de pensamentos e ideias, assim como esclarecer regras e limites na escola. Para isso, o psicopedagogo pode desempenhar sua função, que envolve auxiliar os profissionais da educação e intervir nas relações da comunidade escolar, a fim de favorecer o processo de escuta e troca.

\subsection{Impactos da violência na subjetividade do educador}

No momento em que o professor presencia situações de violência dentro do seu ambiente de trabalho, ele vivencia uma série de sentimentos e frustrações, por não saber lidar com o ocorrido e por lhe causar medo e insegurança. Essas consequências negativas geradas pela violência escolar podem comprometer sua estrutura psíquica, caso não enfrente as situações e não aprenda a lidar com elas.

Ao se referirem aos sentimentos vivenciados no momento da situação de violência dentro do espaço escolar, os entrevistados relataram que sentem medo, impotência, desmotivação e desorientação diante do cenário violento.

Ao presenciar brigas entre os estudantes, o participante $\mathrm{P} 1$ relatou:

Tem que pedir para eles pararem, como tu é [sic] o adulto ali, né? Só que ao mesmo tempo em que tu vê que tem que fazer isso, tem que ter respeito. Tu não pode tocar no aluno [sic], mesmo sem querer, porque daí vem todo um transtorno em volta, né? Então, eu fico com receio, eu não sei o que fazer primeiro [...].

Assim, constatou-se despreparo e desconhecimento por parte do professor, além do medo de enfrentar e lidar com a situação de violência no dia a dia da escola. Conforme Galvão et al. (2010), os professores declaram ser despreparados para lidarem com esse tipo de problema. 
Evidenciou-se também através dos relatos, que há dificuldade em lidar em relação ao conceito de autoridade, conforme o entrevistado P1 comentou:

[...] eu tenho medo de chegar perto, de pegar e arranhar sem querer. Porque aí "bah", daí, porque tu fez isso, né? Então, geralmente, eu peço, "vamos parar" [... ]. Eu vejo que tá surgindo [sic] uma situação que pode gerar uma agressão. Então, eu já vou devagarzinho lá, já vou pedir para parar com isso. Eu não sei como vou agir no momento, para lidar com isso, eu não sei até que ponto eu posso ir para não agredir.

Dessa forma, percebe-se que o conceito de autoridade está passando por diversas transformações, devido, principalmente, ao processo de democratização vivido na sociedade, onde a ideia clássica de autoridade professor com o aluno, como modelo de explicação e entendimento, sofreu mudanças nos últimos anos (GALVÃO et al., 2010).

Sobre as intervenções dos professores nas brigas dos alunos, o participante P4 afirmou:

[...] sou privilegiada porque eu não tive esse tipo de situação a mais, que tu conversasse [sic], gritasse, sentasse, que tu não consiga resolver entre eles mesmos [sic]. Eles param quando eu consigo fazer a intervenção [...]. A gente vai até um certo ponto da capacidade da gente. Tu não pode [sic] intervir também se agarrando no aluno que está agredindo alguém. Eu não interfiro nesse sentido. Mas, falar mais alto, conversar, chamar a direção da escola, os próprios colegas. Tem alunos bem maiores que a gente, eles mesmos interferem, param [...]

Em concordância, Marriel et al. (2006) assevera que, quando há autoritarismo e abuso de poder por parte do professor, cria-se uma barreira para a relação empática, que é muito necessária para a proteção e o cuidado do aluno dentro da escola.

Ainda, o participante $\mathrm{P} 1$ relatou:

[...] desde o tom de voz que eles usam, dependendo como eles falam, eu considero como eu sendo agredida por eles [...]. Tu não sabe [sic] até que ponto tu pode ir. Se a gente tivesse uma formação, [...] um auxílio, um suporte, né? [...] É a tua palavra contra a do aluno. Hoje em dia, a tua palavra não vale nada, a do aluno vale [...]. 
Essa crise na autoridade passa por todos os conjuntos de relações, nas mais diferentes instituições da sociedade contemporânea, e repercute diretamente na escola, como no caso de alguns professores que não sabem lidar com essa situação nem se posicionar diante de tal. Para Witter (2010, p. 11), "a violência prejudica a saúde biopsicossocial das pessoas, afeta a saúde da sociedade e pode ter consequências trágicas". A figura do professor pode ser um dos principais agentes praticantes da violência dentro da escola, o qual, conforme Witter (2010), pode se deparar com a sua falta de competência para administrar a sala de aula, para realizar o controle através da didática, interferindo no comportamento e na produtividade dos alunos. Tais fatores podem levar o professor a gritar, esbravejar, agredir verbalmente ou fisicamente seu aluno, sua família e seus valores. Tudo isso acaba repercutindo negativamente na escola, principalmente nas inter-relações, e causa sofrimento psíquico aos sujeitos envolvidos na violência escolar.

Apesar dessas situações de conflitos professor-aluno, o educador deve ter como principal objetivo a capacidade de desenvolver a solidariedade, a autoestima, o envolvimento emocional com seus alunos, para que assim possa propiciar uma transformação na formação moral e social dos estudantes (ANSER et al., 2003).

Ao relatar sobre o sofrimento causado dentro da sala de aula pela violência, a participante P2 propôs:

\begin{abstract}
Ah, eu me senti muito mal, me senti desmotivada. Porque vida de professor não é fácil, né? [...] Tem muitos problemas em didática. Então, tem que preparar uma boa aula [...]. Às vezes, vou dormir a 1 hora da manhã, porque eu gosto. Eu gosto de fazer, me envolvo. Só que, às vezes, eu chego na sala de aula e [...] um aluno trata mal, fala com arrogância, isso desestimula um monte, né? [...].
\end{abstract}

Conforme Pereira (2003), esses acontecimentos agressivos tendem a desencadear no indivíduo mecanismos de proteção, expressos por sentimentos de hostilidade e defesa, que são manifestados sob diferentes formas e percebidos por constantes frustrações. Dessa forma, evidenciou-se que a violência está tão presente na escola que se configura como natural e banalizada, pois ela se torna corriqueira e faz parte do contexto da instituição. Para Pereira (2003), os educadores apontam que a violência mais clara está nas relações com os alunos e é expressa através de ameaças aos professores, agressões verbais, físicas e psicológicas. 
Portanto, a violência que se configura dentro do espaço escolar, manifestada através dos comportamentos dos alunos, implica em professores desanimados e sem vontade para trabalhar, o que acarreta em uma realidade insuportável. A participante $\mathrm{P} 3$ relatou:

\begin{abstract}
[Me sinto] impotente, claro, nervosa pela situação. E acredito também que despreparada para isso. A gente fica meio paralisada, né? De ver dois alunos brigando [...]. A violência está bem presente. Às vezes, não é só briga, mas tem muita agressão entre eles [...]. Não chegaram a me agredir fisicamente, mas me ameaçavam. Aconteceu de mães me ameaçarem, de baterem em mim por motivos que eu nem tinha conhecimento ainda. Vieram até mim querendo me bater, eu não sei exatamente o porquê. Sofri xingamentos.
\end{abstract}

Ainda, nessa direção, o participante P5 relatou: "às vezes, [sinto-me] até impotente em certas circunstâncias, a gente não sabe o que fazer. A gente busca alternativas, muitas vezes".

Através desses relatos, podemos retomar uma proposição de Oliveira e Martins (2007), os quais afirmam que, diante dessa realidade, encontra-se um professor impotente, o qual se sente desorientado nesse cenário caótico ou se coloca numa postura de indiferença. Quando isso acontece, conforme os autores, tanto o professor quanto o aluno são violentados diante de suas vontades e necessidades. Para Souza (2008, p. 120):

\footnotetext{
Se as formas aparentes da violência são de fácil percepção, as formas psicológicas ocasionadas por ameaças, humilhações, intimidações, rejeição e desrespeito, nem sempre são percebidas e, muitas vezes, podem ser ainda mais graves.
}

Dessa forma, percebeu-se, através dos relatos dos entrevistados, que as ameaças sofridas durante as situações violentas geram sofrimento psíquico e criam um ambiente de segregação dentro da escola.

Quanto à situação como um todo, o participante P4 relatou:

É desagradável, mesmo, porque [...] essa não é a minha função dentro de uma escola. É difícil porque tu vem [sic] com [...] uma proposta de ensinar, de dar aula, de conversar. Aí, tu tem que, simplesmente, fazer a separação daquilo, daquela situação. É bem desagradável. Tu fica [sic] até, às vezes, meio sem ação, porque as coisas estão tão violentas, que tu chama alguém da direção para te alicerçar. Senão, fica difícil. 
Verificou-se que, pela falta de preparo e informações, os professores negam ou tendem a repassar a responsabilidade de lidar com as situações de violência vividas dentro da escola. Assim, seria necessário que a escola oferecesse ferramentas para que os educadores identificassem as formas e as consequências, a fim de buscar solucionar os atos de violência no espaço escolar. Em concordância, Souza (2008) assevera que se deve conscientizar a comunidade escolar sobre as formas de violência e sobre as consequências na vida do indivíduo, bem como analisar os inúmeros fatores externos que influenciam no comportamento dos estudantes na vida escolar, além de fornecer subsídios para que os professores identifiquem e busquem minimizar ou solucionar o problema.

De acordo com Njaine e Minayo (2003), é através das atitudes de rupturas de preconceitos, medos e silêncios dos professores, diante do conhecimento das situações violentas na escola envolvendo alunos, que poderá ocorrer uma transformação no cotidiano escolar como, por exemplo, a partir do diálogo, diminuindo a distância entre professor e aluno e revertendo os comportamentos agressivos.

Sendo assim, notou-se que os impactos na subjetividade dos professores causados pela violência escolar são diversos e podem interferir e causar uma série de situações críticas em sua vida, como: falta de motivação para trabalhar, medo, insegurança, despreparo e sentimentos de impotência. Porém, os entrevistados se mostraram interessados em minimizar ou solucionar o problema através do diálogo, de elogios, de preparar uma boa aula, além de pedirem suporte para aprender a lidar melhor com esse fenômeno.

Dessa forma, torna-se fundamental refletir criticamente a respeito da relevância da presença do psicopedagogo dentro da instituição escolar, o que pode contribuir a despertar a necessidade de prevenir, minimizar e/ou solucionar os casos de violência nesse ambiente. De acordo com Soares e Sena (2012), é extremamente pertinente um trabalho de estudo e análise que reflita sobre a finalidade do psicopedagogo e a sua contribuição no contexto escolar. 


\title{
3.4 A prevenção da violência: desafios e possibilidades
}

A escola ainda representa um dos pilares para a construção da subjetividade de todos os indivíduos integrantes desse contexto. Porém, quando esse espaço encontra-se doente, violento e agressivo, deve-se pensar em alternativas capazes de prevenir, minimizar e/ou solucionar essas situações deploráveis na sociedade contemporânea.

Ao serem solicitados a dar a sua opinião sobre as formas de prevenção da violência na escola, os professores apontaram como principais alternativas: políticas públicas, participação da família dentro da escola e capacitação/formação dos professores.

Sobre possíveis maneiras de se prevenir a violência na escola, o entrevistado P1 relatou:

\begin{abstract}
Políticas públicas; leis que nos amparassem. [...] A gente fica desamparado. Para melhorar, só se mudasse o olhar que se tem. Como a gente enxerga o professor, como os governantes enxergam o professor. Esse seria o jeito, eu acho, para a gente poder fazer alguma coisa para melhorar. $E$ também uma coisa que eu percebo [...]: se a família tivesse um olhar também, olhar para o professor de uma maneira diferente, os alunos também veriam [...].
\end{abstract}

Em concordância, Witter (2010) assevera que a violência prejudica tanto fisicamente quanto psicologicamente os indivíduos envolvidos e que, consequentemente, é necessária uma legislação mais rigorosa e efetiva, que seja cumprida, mas, também, um preparo apropriado para os profissionais da instituição escolar.

Sobre as políticas públicas, o entrevistado P5 relatou: "[...] eu acredito que deveria existir uma lei reforçando o professor [...]. Até onde que vamos conseguir modificar essa situação? Porque ninguém vai vir aqui e bater de frente. Tem que procurar alternativas".

Segundo Njaine e Minayo (2003), os professores demonstram carência de informação, conhecimentos e debates sobre leis, como o Estatuto da Criança e do Adolescente (ECA). Isso foi evidenciado através do relato da participante P2: "[...] ainda tem as leis que protegem eles, a gente não né? Eu então, enquanto professora, fico desamparada [...]". 
No final da década de 80 , e durante os anos 90, surgiram condições que favoreceram e estimularam transformações no sistema de ensino, as quais possibilitaram interferência nas interações na escola, com o intuito de reduzir os índices de violência, envolvendo professores, alunos e profissionais da educação (GONÇALVES; SPOSITO, 2002). Como exemplo dessas mudanças, podem ser destacadas as novas formas de organização da escola por ciclos, as avaliações discentes e as orientações curriculares, além da aprovação da Lei de Diretrizes e Bases (LDB), em 1996.

Já em relação aos recursos e ao preparo para os profissionais da educação, o participante P2 disse:

[...] eu acho que várias coisas têm que mudar. Eu acho que os órgãos públicos têm que incentivar a educação a ter mais recursos, e não é recursos [sic] como computador, dar cursos para os professores fazerem. Para tua aula ficar com qualidade, né? [...].

Para Witter (2010), os professores não estão bem preparados e não contam com uma orientação psicoeducacional. Sobre o despreparo docente, o entrevistado P3 acrescentou:

[...] eu acho que a gente não tem uma formação. Os cursos de formação continuada deveriam dar uma ênfase [sic] para isso, porque está muito forte, muito constantes esses casos [sic]. E a gente não tem uma formação específica para lidar com a violência na escola [...].

Como se pode perceber, os professores quase sempre acabam padecendo de uma espécie de sentimento de "mãos atadas", quando confrontados com situações atípicas, e por não saberem lidar com os problemas da violência na sala de aula.

Assim, verificou-se que é preciso levar em conta a necessidade de haver uma melhora na formação dos docentes e assegurar-lhes amparo que supra suas dificuldades e necessidades durante a prática escolar. Ainda, os discursos dos professores valorizam cada vez mais o exercício contínuo da reflexão sobre as consequências de suas ações no seu ambiente de trabalho. 
Desse modo, é relevante destacar a importância de oferecer apoio constante aos profissionais da educação e fornecer atualização e capacitação permanente durante toda a vida profissional.

Constatou-se que os professores entrevistados afirmam que deveriam discutir com os alunos acerca do fenômeno da violência escolar, mas não se julgam preparados para desenvolver esse tipo de atividade. Sentimentos como impotência, medo, angústia e revolta, geralmente, são comuns entre os educadores que têm que lidar com a violência na escola (NJAINE; MINAYO, 2003).

Em relação à participação da família na escola, o entrevistado P3 afirmou:

Eu acredito que, antes de tudo, a família [deve] estar mais presente [...] que a gente pensasse junto sobre como lidar com isso [...]. Tanto os professores tinham que ter formação, tinham que ter a capacitação e o apoio, quanto a família, os pais [...].

Tanto o diálogo com a família quanto a participação dos pais na escola foram ressaltadas como fatores de prevenção da violência escolar. A família foi muito criticada pela maioria dos participantes da pesquisa. Para Njaine e Minayo (2003), os professores denunciam a família pela pouca participação na educação, no diálogo, na presença efetiva e na imposição de limites aos seus filhos. Ainda, ao descrever o descaso da família, o entrevistado P4 fez questão de salientar a sua função dentro da instituição escolar:

Olha, eu acredito assim, que a família tinha que estar mais presente, a
família tinha que assumir mais o seu filho, a questão familiar tinha que ser
dada com bem mais valores. A escola já oferece oficinas, palestras,
conversas. [...] Então, por mais que a escola intervém [sic], eu acredito que
a família tinha que ser bem mais preparada e presente dentro da escola. A
questão educação: educação familiar, valores da família. Vindo de casa, eu
acho que a metade dos problemas que a gente tem dentro de uma escola
se resolveria [...].

Portanto, evidenciou-se que a família foi apontada pelos entrevistados pela sua ausência na vida escolar dos filhos, assim como nas etapas primordiais de crescimento e de desenvolvimento.

Cabe aqui ressaltar a função da família como instrumento de imposição de limites educacionais e responsável pelo ensinamento de valores fundamentais à formação digna do ser humano. Nessa direção, devem ser reconhecidos os depoimentos dos professores acerca da violência que passam pela necessidade de Cad. de Pesq. Interdisc. em Ci-s. Hum-s. Florianópolis, Santa Catarina, Brasil, ISSN 1984-8951 
haver o diálogo com a família sobre as causas desse fenômeno dentro da escola. Porém, "cabe aqui também interrogar e questionar a quase total responsabilização da família por esses problemas que são muito mais amplos" (NJAINE; MINAYO, 2003, p. 129).

Diante da violência, o desafio maior é o reconhecimento das suas diversas manifestações e complexidades, e não apenas reduzir a uma única fonte as causas desse fenômeno social. Assim, tanto a família quanto a escola devem servir como mediadoras e facilitadoras, a fim de possibilitar ações de prevenção à violência.

Segundo Anser et al. (2003, p. 70), "a escola, como instituição que faz parte da sociedade, sofre os reflexos dos fatores de violência externos que têm gerado conflitos manifestados dentro da sala de aula, comprometendo o aprendizado e as relações interpessoais".

Com base nessas considerações, é necessário enfatizar que cabe aos formuladores de políticas públicas educacionais buscarem hipóteses sobre o grave problema da violência escolar e propor ações concretas, visando solucioná-las e/ou minimizá-las. Conforme Gonçalves e Sposito (2002), o maior desafio a ser enfrentado é saber que políticas públicas devem ser implementadas de forma que "pacifiquem" o ambiente escolar sem atentar contra os direitos humanos.

Dessa forma, cabe aqui ressaltar que o psicopedagogo, dentro da instituição escolar, é de extrema importância, porque estimula o desenvolvimento das relações interpessoais, o estabelecimento de vínculos, procura envolver a equipe escolar, ajudando-a a ampliar o olhar em torno do aluno, e auxilia este último a superar os obstáculos encontrados na escola (SOARES; SENA, 2012).

\section{Considerações finais}

A partir da pesquisa realizada, foi possível perceber que não há dúvidas de que algo deve ser feito para reduzir a violência no ambiente escolar, pois ficou evidente que esse fenômeno social tem gerado medo, insegurança, humilhação e impotência no interior da escola, principalmente no que se refere aos professores. Constatou-se que alunos e professores são comumente os atores mais lembrados e responsáveis quando se discute a violência na escola. 
Segundo Pereira e Williams (2010), no que diz respeito à violência escolar, é necessário o enfrentamento dessa questão, indicando a ocorrência das situações de violência, quais são os envolvidos, quem são os autores, as vítimas e/ou as testemunhas da violência, os tipos e as especificidades de violência.

Percebeu-se, diante dos relatos, que é corriqueira a prática da violência na escola, sob as mais variadas formas, como brigas, agressões verbais, humilhações, ameaças, com consequências negativas para toda a comunidade escolar, interferindo significativamente no processo de ensino e aprendizagem. É importante salientar que todos os professores entrevistados apontaram que as formas de violência que mais ocorrem na escola são a agressão e a humilhação verbais, conforme já mencionado.

Notou-se, ainda, que diante das situações que geram a violência dentro do ambiente escolar, os professores se sentem desconfortáveis, inseguros e desinformados para buscarem alternativas, a fim de minimizar e/ou solucionar o problema e eliminar as causas desses acontecimentos constrangedores.

Verificou-se que os impactos da violência na subjetividade dos professores são muitos e geram repercussões extremamente negativas em suas vidas, como desmotivação para trabalhar, medo, insegurança, impotência e despreparo para lidar com as situações de agressão na escola, levando ao empobrecimento do seu fazer, com sérios prejuízos à interação professor-aluno. Todavia, os entrevistados demonstraram interesse em buscar formas e possibilidades para amenizar esse fenômeno na escola, através de diálogos, pois desejam e solicitam informações para aprenderem a lidar com tal realidade, alcançando seus objetivos profissionais.

Outro aspecto extremamente relevante abordado pelos participantes ao serem questionados em relação a formas de prevenção à violência é a consideração de que a família, por ser a responsável pela educação e imposição de limites e promoção de diálogo com os filhos, deve estar mais presente e ativa na escola.

Os professores relataram, ainda, a necessidade de se implementarem políticas públicas que abranjam o ambiente escolar, com o intuito de solucionar esse grave problema que aflige à comunidade escolar.

Diante do exposto, cabe à escola refletir e discutir sobre as questões que geram desconforto e frustrações no seu dia a dia, entre as quais se destacam a violência, suas formas de prevenção e intervenções, bem como as possíveis 
consequências na subjetividade dos sujeitos envolvidos nesse fenômeno. A escola é fundamental para o desenvolvimento do indivíduo e deve ser uma das provedoras de estimulação das habilidades intelectuais, sociais, bem como do senso crítico.

Sendo assim, evidencia-se a importância do olhar e da escuta psicopedagógica, em conjunto com a equipe pedagógica, através de uma abordagem multidisciplinar, envolvendo o psicólogo, o assistente social e demais profissionais que possam contribuir com o enfrentamento da questão, pois estes são elementos complementares e contribuem no processo de compreender o fenômeno social da violência. Nessa direção, Souza (2010) ressalta que a escuta psicopedagógica se torna um fator predominante no atendimento aos professores, pois Ihes possibilita vez e voz para se expressarem.

Salienta-se que o papel do psicopedagogo é, por meio de uma atuação diferenciada, apoiar e orientar os professores, através de ações e estratégias em parcerias com as famílias, a fim de buscar prevenir problemas e conflitos escolares.

Diante da realidade já citada, é primordial que haja uma reflexão a respeito do fenômeno da violência escolar, com a devida contribuição do psicopedagogo nesse processo, pois este irá orientar e complementar a equipe, fortalecendo-a diante do desafio da violência escolar. Sendo assim, o psicopedagogo pode atuar tanto de forma preventiva quanto terapêutica, para compreender os processos de desenvolvimento e as inter-relações, podendo envolver o preparo dos profissionais da educação e recorrer a estratégias a partir das situações de violência que surgem.

Portanto, considerando que os dados desta pesquisa se referem a uma amostra muito restrita, sugere-se que sejam realizadas outras pesquisas sobre o tema, com o intuito de contribuir com a análise das repercussões e das implicações da violência na vida dos professores, e das possíveis ações que venham a instrumentalizar a prática educativa e que sejam capazes de minimizar os efeitos da violência na escola. Além disso, é importante analisar melhor os elementos que compõem a relação professor-aluno, levando em conta também a parceria com as famílias, a fim de verificar as causas e propor soluções plausíveis. 


\section{Referências}

ANSER, M. A. C. I. et al. Avaliação do conceito violência no ambiente escolar: visão do professor. Psicologia: teoria e prática, v. 5, n. 2, p. 67-81. 2003. Disponível em: $<$ http://editorarevistas.mackenzie.br/index.php/ptp/article/view/1191/889>. Acesso em: 13 dez. 2012.

BARDIN, L. Análise de conteúdo. Lisboa: Edições 70, 2004.

CHRISPINO, A.; DUSI, M. L. H. M. Uma proposta de modelagem de política pública para a redução da violência escolar e promoção da Cultura de Paz. Ensaio: Avaliação e Políticas Públicas em Educação, Rio de Janeiro, v. 16, n. 61, p. 597-624. 2008.

DANI, L. S. C. Escola: os conflitos sócio morais e a construção da personalidade moral. Educação, Santa Maria, v. 35, n. 3, p. 381-394, 2010. Disponível em:

$<$ http://cascavel.ufsm.br/revistas/ojs2.2.2/index.php/reveducacao/article/viewFile/2350/ 1417>. Acesso em: 04 out. 2011.

FERNANDÉZ, A. O saber em jogo: a psicopedagogia propiciando autorias do pensamento. Trad. Neusa Kern Hickel. Porto Alegre: Artmed, 2001.

GALVÃO, A. et al. Violências escolares: implicações para a gestão e o currículo. Ensaio: Avaliação e Políticas Públicas em Educação, Rio de Janeiro, v. 18, n. 68. 2010.

GIL, A. C. Métodos e técnicas de pesquisa social. São Paulo: Atlas, 1995.

GONÇALVES, L. A. O.; SPOSITO, M. P. Iniciativas públicas de redução da violência escolar no Brasil. Cadernos de Pesquisa, n. 115, p. 101-138. 2002.

KERLINGER, F. N. Metodologia da pesquisa em ciências sociais. São Paulo: EPU, 1980.

MARCONI, M. A.; LAKATOS, E. M. Técnicas de Pesquisa: planejamento e execução de pesquisas, amostragens e técnicas de pesquisas, elaboração, análise e interpretação de dados. 4 ed. São Paulo: Atlas, 1999.

MARRIEL, L. C. et al. Violência escolar e autoestima de adolescentes. Cadernos de Pesquisa, v. 36, n. 127, p. 35-50. 2006. 
MINAYO, C. Pesquisa social: teoria, método e criatividade. Petrópolis: Vozes, 1994.

MINAYO, C. Pesquisa social: teoria, método e criatividade. 25 ed., Petrópolis: Vozes, 2007.

MINAYO, C. Pesquisa Social: teoria, método e criatividade. 27 ed. Petrópolis,: Vozes, 2008.

MORAES, R. Análise de conteúdo. Revista Educação, Porto Alegre, v. 22, n.37, p.732. 1999 .

NETO, A. A. L. Bullying - comportamento agressivo entre estudantes. Jornal de Pediatria, v. 81, n. 5, p. 164-172. 2005.

NJAINE, K.; MINAYO, M. C. S. Violência na escola: identificando pistas para a prevenção. Interface - Comunicação, Saúde, Educação, v. 7, n. 13, p. 119-34. 2003. Disponível em: <http://www.scielo.br/pdf/icse/v7n13/v7n13a08.pdf>. Acesso em: 10 out. 2011.

OLIVEIRA, E. C. S.; MARTINS, S. T. F. Violência, sociedade e escola: da recusa do diálogo à falência da palavra. Psicologia \& Sociedade, v. 19, n. 1, p. 90 - 98. 2007.

ORTEGA, R.; REY, R. Estratégias educativas para prevenção da violência. Brasília: UNESCO, UCB, 2002.

PEREIRA, M. A. Violência nas escolas: visão dos professores do Ensino Fundamental sobre esta questão. Escola de Enfermagem de Ribeirão Preto, São Paulo, 2003. Disponível em: <http://www.teses.usp.br/teses/disponiveis/22/22131/tde-21052004142723/pt-br.php>. Acesso em: 07 out. 2011.

PEREIRA, A. C. S.; WILLIAMS, L. C. Reflexões sobre o conceito de violência escolar e a busca por uma definição abrangente. Temas em Psicologia, v. 18, n. 1, p. 45-55. 2010. Disponível em: <http://www.laprev.ufscar.br/documentos/arquivos/artigos/2010stelko-pereira-e-williams.pdf>. Acesso em: 19 fev. 2013.

PRIOTTO, E. P.; BONETI, L. W. Violência escolar: na escola, da escola e contra a escola. Revista Diálogo Educacional, v. 9, n. 26, p. 161-179. 2009.

RISTUM, M.; BASTOS, A. C. Violência urbana: uma análise dos conceitos de professores do ensino fundamental. Ciência \& Saúde, v. 9, n. 1, p. 225-239. 2004. Cad. de Pesq. Interdisc. em Ci-s. Hum-s. Florianópolis, Santa Catarina, Brasil, ISSN 1984-8951 v.14, n.105, p.88-119, ago/dez 2013 
RUSS, J. Dicionário de filosofia. In: OLIVEIRA, E. C. S.; MARTINS, S. T. F. Violência, sociedade e escola: da recusa do diálogo à falência da palavra. Psicologia \& Sociedade, v. 19, n. 1, p. 90-98. 2007.

SANTOS, J. V. T. A violência na escola: conflitualidade social e ações civilizatórias. Educação e Pesquisa, São Paulo, v. 27, n. 1, p. 105-122. 2001. Disponível em: $<$ http://www.scielo.br/scielo.php?script=sci arttext\&pid=S1517-97022001000100008>. Acesso em: 06 out. 2011.

SILVA, J. O.; RISTUM, M. A violência escolar no contexto de privação de liberdade. Psicologia: Ciência e Profissão, Brasília, v. 30, n. 2. 2010. Disponível em: $<$ http://pepsic.bvsalud.org/scielo.php?script=sci arttext\&pid=S141498932010000200002>. Acesso em: 04 out. 2011.

SOARES, M.; SENA, C. C. B. A contribuição do psicopedagogo no contexto escolar. Associação Brasileira de Psicopedagogia, p. 1-9, abr. 2012. Disponível em: <http://www.abpp.com.br/artigos/126.pdf>. Acesso em: 01 jan. 2013.

SOUZA, M. R. Violências nas escolas: causas e consequências. Caderno Discente do Instituto Superior de Educação, Brasília, ano 2, n. 2, p. 119-136. 2008.

Disponível em: <

http://www.faculdadealfredonasser.edu.br/files/pesquisa/Artigo\%20VIOL \%C3\%8ANCIA $\% 20$ NAS $\% 20$ ESCOLAS $\% 20-$

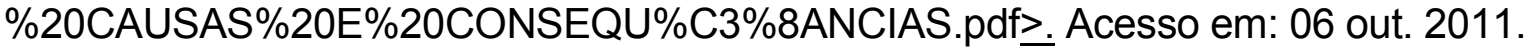

SOUZA, M. V. C. A escuta psicopedagógica aos professores na escola. Associação Brasileira de Psicopedagogia, maio, 2010. Disponível em: <http://www.abpp.com.br/artigos/108.pdf>. Acesso em: 19 fev. 2013.

VELÁSQUEZ, C. D. C.; CUNHA, J. L. Um olhar sobre a violência: refletindo a escola. Travessias, 05 ed. 2008. Disponível em: <http://www.unioeste.br/prppg/mestrados/letras/revistas/travessias/e d_005/artigos/educacao/pdfs/UM\%200LHAR.pdf>. Acesso em: 04 out. 2011.

WITTER, G. P. Ponto de vista: violência e escola. Temas em Psicologia, v. 18, n. 1, p. 11-15. 2010. Disponível em: $<$ http://pepsic.bvsalud.org/scielo.php?pid=S1413389X2010000100002\&script=sci_arttext>. Acesso em: 06 out. 2011.

\section{Artigo:}

Recebido em: 17/07/2013

Aceito em: 06/12/2013 